\title{
TEATRO E TEORIA: A Filha Natural EM BERLIM
}

\section{RUBENS RODRIGUES TORRES FILHO}

1. Na virada do século XVIII para o XIX, refazendo-se ainda do abalo causado na cosciência européia pela Revolução Francesa, Goethe escreve a tragédia (Trauerspiel) A Filha Natural, com um assunto que the foi sugerido por Schiller e inspirado pela leitura das Mémoires Historiques de Stephanie-Louise de Bourbon-Conti (Paris, 1798), onde são narradas as desventuras de uma bastarda, da nobreza francesa, no periodo de insegurança que se seguiu à Revolução. Em 1803 a peça teve duas récitas em Berlim, com estrondoso fracasso de público e de crítica, chegando a ser vaiada no primeiro dia, e teve na platéia, nas duas apresentações, um espectador - talvez o único - entusiasmado: o filosofo Johann Gottlieb Fichte.

A peça põe em cena o destino de Eugenie, única personagem dotada de nome próprio, mesmo assim alegórico, alusão a sua eminente origem: é filha bastarda do Duque, tio do Rei, e da Princesa - cuja recente morte vai permitir que de sua existência oculta ela passe agora ao brilho de seu verdadeiro lugar no mundo. Reconhecida pelo pai e pelo soberano, ela poderá enfim aparecer ou, na linguagem da morfologia de Goethe, desabrochar (Erscheinen). Mas as sombrias perspectivas que se op̃em a esse desejo já estão simbolizadas no primeiro ato. Logo após ter o Duque confiado ao Rei, numa pausa da caçada, sua paternidade secreta, chega até eles o alarido e a notícia de que a audaciosa amazona desconhecida, que faz parte da comitiva e é (segredo público, que todos fingem ignorar) a filha do Duque, acaba de sofrer uma queda fatal - e entra em cena carregada como morta, para desespero do pai.

Ao recobrar os sentidos, Eugenie pensa estar sonhando: seu pai a reconheceu perante o Rei, e este, encantado, promete apresentá-la à corte em sua festa de aniversário que se aproxima. Mas, cautela. É preciso que o segredo seja guardado até lá, pois o soberano está cercado de in. trigantes e a situação política é inquietadora. Pressente-se, enigmati- 
camente, que mesmo entre o Rei e o Duque há desconfiança e perigo. Nem mesmo é permitido a Eugenie dar expansão a sua alegria ou usar a chave, que o Duque lhe confia, do cofre-armário contendo as vestimentas e adereços que convêm à sua nobre condição: ela tem um irmão, que certamente não verá com bons olhos sua ascensão. A filha natural consolase, pensando que suas qualidades de brandura e de espírito o conquistarão, e de qualquer modo seu entusiasmo supera qualquer inquietação.

Mas já nesse momento, em casa, o Secretário conspira com sua noiva, a Preceptora, procurando obter sua colaboração no plano - que interessa ao irmão - para afastar Eugenie de seus direitos. A Preceptora, muito afeiçoada a Eugenie, não tem saida: aceitará conduzir a pupila ao exílio, enquanto os cúmplices espalham a notícia de sua morte, pois o Secretário não esconde que afastá-la é a solução mais branda. "Eugenie! se tu pudesses renunciar..." Mas Eugenie, que chega à casa atônita de felicidade e corre a seu quarto para escrever um soneto exprimindo seu deslumbramento, só tem olhos para a esperança e não pode pressentir o perigo. Quando recebe o cofre-armário, da parte do pai, sua sofreguidão é mais forte que a palavra dada: ela vai experimentar aqueles ornatos, presentear a Preceptora, compartilhar com ela sua alegria, sem dar ouvidos às suas sombrias advertências. "- Irreversível, cara amiga, é minha felicidade. - O destino, que te atinge, é irreversivel."

O terceiro ato mostra a trama consumada: O Secretário e o Clérigo, seu cúmplice, convencem o Duque da morte de Eugenie, lembrando a ele, que quer morrer, seus deveres de estadista naquele momento de crise política. Eugenie, que o pai acredita morta em um acidente de equitação, encontra-se no porto mais afastado do reino, conduzida pela Preceptora, que tem ordens de embarcá-la para as Ilhas. Ao generoso e íntegro Conselheiro Judicial, que ali encontram, enquanto esperam o momento do embarque, a Preceptora exibe o salvo-conduto de que é portadora, conferindo a ela plenos poderes sobre a pupila. O jurista se estarrece com aquele ato de força, mas tem de acatar as explicações que lhe são dadas: a existência de Eugenie se tornou o pomo da discórdia entre dois poderosos partidos, cujo choque ameaça a estabilidade do reino. Há para ela, entretanto, uma chance de perdão: basta que aceite renunciar a sua condição nobre, casando-se com um burguês.

Ãquele homem de aspecto digno, que se mostra tão perturbado com sua sorte, Eugenie se confia inteiramente, revelando sua perplexidade diante do monstruoso ato de que é vítima, diante dessa sua segunda queda - castigo por sua inocente indiscrição? inveja do irmão? conspiração que envolve o pai e o Rei e ameaça destruir o mundo? Ele não pode dar-lhe explicaçð̃es, poderes mais alfos se opð̃em a que ela readquira sua condição. Mas, seduzido pela excelência de Eugenie, oferecelhe o único meio de salvação que resta, propondo-lhe casamento. Em vão: os sonhos de glória de Eugenie ainda estão próximos demais, ela sabe que isso representaria uma renúncia definitiva - e só pode exprimir 
sua gratidão pela nobre proposta. Nem mesmo os apelos da Preceptora a persuadem a lançar mão desse derradeiro recurso. Convencida de que a acompanhante faz parte da conspiração, Eugenie decide apelar para a população do porto, que entretanto passa indiferente e a toma por louca.

Seus pedidos de socorro, que a Perceptora não tenta impedir, são uma sucessão de decepções. O jovem Governador, que se aproxima com seu séquito para ver a partida do navio, simpatiza com a desconhecida e se dispõe a ajudá-la, mas afasta-se imediatamente após lançar os olhos ao salvo-conduto. Eugenie quer ver esse papel tão poderoso. A Preceptora não o recusa, mas falta coragem à moça: ao risco de aumentar seu desespero vendo a assinatura do Duque ou do Rei, Eugenie prefere resignar-se e buscar refúgio na religião. Corre para o grupo de freiras que se aproxima e suplica à Abadessa que a acolha junto a si. Mais uma vez, quando a Abadessa vai tomá-la nos braços, a Preceptora intervém e exibe a carta, que decide tudo. Mesmo a igreja se curva diante de poder tão alto. Seria Deus? Eugenie se enche de bravura e desdobra o papel: "A mão e o selo do Rei!"

Aproxima-se o momento de embarcar para o exílio. A infeliz quer atirar-se ao mar, mas hesita. Entre a morte, o exílio e o aviltamento, seu espírito não descansa. $\mathrm{O}$ medo de um a precipita para o outro. Um monje se aproxima. Eugenie quer consultá-lo como a um oráculo. $\mathrm{O}$ velho sábio só pode aconselhá-lha em termos gerais: - Entre dois males detestados, escolhe o que te deixa mais espaço para atos devotos. Em vez do casamento sem amor que a ameaça, praticar boas obras e levar consolo aos selvagens da Ilhas? Mas no fundo de suas palavras Eugenie adivinha um conselho mais urgente, uma realidade mais ter'rível: salvar-se, abandonar aquele reino ameaçado pela ruína.

E Eugenie compreende. $\mathrm{O}$ imenso poder do Rei, expresso naquele salvo-conduto, é na verdade uma confissão de impotência: o ato de um "fantasma que se afaina inutilmente na ilusão de capturar a posse perdida". E abandonar a pátria, nessa hora de perigo? Ficando, mesmo desconhecida, mesmo rebaixada a uma condição obscura, ela não poderá um dia, talvez, ser valiosa?

Quando o Conselheiro Judicial vem trazer-lhe seu presente de despedida, lamentando perder tão cedo a felicidade que por um instante lhe acenara, Eugenie the comunica sua mudança de decisão, assumida não por covardia, mas por bravura. Aceita pertencer-lhe como esposa, desde que ele queira recebê-la como um irmão e lhe permita viver retirada, desconhecida de todos, em sua propriedade no campo, até chegar o dia em que, talvez, laços mais estreitos os unirão. Confiante na palavra daquele homem sério e honesto, Eugenie não hesita mais em consumar sua renúncia. "Recebe disso a prova, a mais alta, que uma mulher lucidamente pode dar! Não vacilo, apresso-me em seguir-te! Eis minha mão: sigamos para o altar!" 
2. No dia 18 de agosto de 1803 , Fichte, de Berlim, escreve a Schiller:

Vi com toda atenção A Filha Natural, de Goethe, as duas vezes que foi levada aqui, e acredito ter-me elevado, por esse meio, a todos os aspectos possíveis da obra. Por mais que eu tenha reverenciado e amado Ifigênia, Tasso e, em outro campo, Hermann e Dorotéia, de Goethe, e tenha considerado dificilmente possivel algo superior, prefiro no entanto essa obra a todas as suas outras e a considero como, cté agora, a mais alta obramestra do mestre. Clara como a luz e, como ela, insondável, em cada uma de suas partes contraindo-se vivamente em absoluta unidade e ao mesmo tempo espraiando-se pela infinidade, como ela. Essa rigorosa coerência orgânica torna totalmente impossível, para mim, querer abs. trair ou omitir qualquer de suas partes. $O$ que na primeira parte ainda não se esclarece totalmente, como as misteriosas alusões a uma relação secreta entre o Duque e seu filho, a secretas maquinaçôes de ambos e de outros ainda, preparam sem dúvida o que está por vir e desde já enchem a alma de um maravilhoso calafrio.

Que uma obra dessa profundeza e simplicidade, ao mesmo tempo, seja captada e apresentada (dargestellt) em seu espírito interior por qualquer companhia teatral existente, é algo a que, sem dúvida, é preciso renunciar. O bom espectador, porém, deve enxergar, através do limitado da encenação (Darstellung), o ideal dela, e através deste a obra. Esse é o caminho que tive de percorrer e que, em se tratando de obras dramáticas, me parece o certo. Pode ser por isso que Zeltner, que começou pela leitura, e a partir dela formou para si mesmo a representação (Darstellung) ideal, ao contemplar a efetiva foi mais dificil de contentar que eu, que de resto não posso gabar-me de ser muito fácil de contentar. Ora, pretender do espectador comum, em primeiro lugar, essa elevação acima do limitado da exposição (Darstellung) - em obras comuns ele é dispensado disso, nelas a exposição (Darstellung) e o assunto (Sache), por serem ambos comuns e rasos, coincidem muito bem -, pretender dele, além disso, uma rigorosa atenção durante duas a três horas, justamente porque o todo é um todo e ele não entende nenhuma das partes se não enten. der todas - enquanto nas peças comuns ele pode estar ausente quando quiser e voltar a estar atento quando quiser e no entanto sempre atina com um todo, ou seja, com um inteiro... grão de areia -, pretender dele, enfim, o sentido, totalmente carente, para a interioridade do ser humano e da ação que se passa nesse palco - por isso direção, cidade e corte acreditam que nos dois últimos atos dessa obra não há ação nenhuma, e certamente Goethe teria podido poupar esses dois atos, pela simples narração: Eugenie dá sua mão a um Conselheiro Judicial -. todas essas pretensôes, compreende-se com que caras são acolhidas. Eu, porém, de minha parte, quanto mais velho fico, e quanto mais me oprime, aqui, todo dia uma estupidez qualquer, e quanto mais obrasmestras vocês nos enviam daí, só me fortaleço cada vez mais no impla. 
cável sentimento de que certamente se deve colocar o melhor, e somente o melhor, diante dos olhos do público, sem nenhuma condescendência com o tédio e o desconforto da incultura, não remendar o ruim e pendurar nele, se Deus ajudar, o bom, mas aniquilar puramente o ruim e criar puramente o bom, e de que o ruim nunca melhorará, a não ser quando simplesmente não se tomar nenhum conhecimento de que o ruim existe.

Entre os atores, a meu ver, Madame Fleck, como Eugenie, leva a palma, de longe. Em particular seu desempenho no segundo ato, na expressão da alegre expectativa no soneto, na fantasia poética logo a seguir depois no vestir os adornos, no irromper de seu nobre sentimento de generosidade etc., foi inspirado e inspirador. Ela não arruinou propriamente nada, de que eu me lembre. Iffland representou (stellte ... dar) muito bem, particularmente no terceiro ato, o pai amoroso, que se desvanece ao pensamento da suposta perda, e causou uma poderosa impres. são sobre seu público; mas permanecem sempre um pai amoroso de uma de suas peças de famílias montanhesas: a fidalguia do primeiro vassalo, cônjuge secreto da altiva Princesa, pai da eminente filha, o significativo do astro sombriamente ameaçador no horizonte político desse reino, se perderam - não em prejuizo da peça ao que me parece, para o verdadeiro espectador: pois quem conhece Iffland de outros papéis não o tomará como idéntico a uma tal personagem e ao aceno do poeta suprirá de bom grado dignidade e elevação e profundeza. Mattausch como Rei esteve bem imponente. Ainda, como Clérigo, Bessel Yque de costume faz papéis insignificantes) merece menção. Não representou sem vigor, $e$ muito da rudeza de seus modos o espectador benevolente poderia levar à conta da vida aldeã do senhor eclesiástico. Bethmann como Conselheiro Judicial não representou com descuido, como quiseram censurar-lhe; mas o que se pode fazer desse órgão sem maleabilidade, monocórdio? Herdt como Monje não se desfez de sua natureza, de pôr os acentos assim como o exige a respiração natural; no entanto, entendia-se tudo e era possível então dizer a si mesmo o papel de outro modo e corretamente. Beschart desincumbiu-se do Governador polido e galante, como é sua maneira; $e$ isso não fez mal ao papel. O papel da Preceptora foi dado a uma cantora, a qual, por uma cautela em si mesma louvável, ao tempo em que sua voz para o canto poderia estar declinando, quer dedicar-se à recitação: Madame Schiel. Ora, esta certamente trouxe consigo a gesticulação do teatro de ópera, mas cantar não podia, e falar não sabia. Acredito, por certo, ter adivinhado a intenção e o significado geral desse papel; mas as palavras, as duas vezes, não ouvi; sobre isso, portanto, ficou uma lacuna no meu conhecimento. Da arraigada superficialidade de Schwadkes - que representou o Secretário - não se pode fazer nenhuma personagem goetheana. Esse homem deveria ser totalmente exilado para as peças de conversação dos ingleses.

Ainda uma anedota, que para mim foi muito edificante e instrutiva. $O$ papel da Freira foi guarnecido, no primeiro dia, por Madame Herdt, a 
qual se portou de tal modo que o público irrompeu em uma sonora gargalhada - e desta vez, aliás, com a mais perfeita razão. Como se arruma a direção no segundo dia? Pois bem, corta inteiramente esse papel apenas mais uma das personagens inúteis, há de ter pensado, que entram em cena nos dois últimos atos - (como, em crescente angústia, todos os meios de salvação têm de ser tentados, antes de se lançar mão do singular recurso final, e como ainda, ao lado disso, devem desfilar perante os olhos do espectador todas as categorias sociais do reino que vai ao encontro de sua ruína, à medida da diminuição de seu espírito, disso esses críticos decerto não desconfiaram) —, mas deixou o papel de Eugenie inalterado, de tal forma que, agora, o olhar ousado para o salvo-conduto da acompanhante segue-se sem intermediário e imediatamente à recusa de vê-lo por medo de enxergar um dos dois nomes amados. Com isso, pois, Goethe que aprenda como tem de fazer para dar mais rapidez à ação, tão freqüentemente demorada em suas obras!

Uma questão: como o Autor concebe a representação (Darstellung) exterior da nação no porto, desse coro, do qual seus representantes se destacam e se entrelaçam na ação? (o que, de passagem, o povo daqui também não capta e a Gazeta de Unger, por exemplo, é de opinião que eles entram e desaparecem como transeuntes desocupados). Deve efetivamente ser visivel pelo menos um começo da incomesurável vida e faina, que então a fantasia prolonga ao infinito, ou deve o espectador enxergar essa multidão como com o olho da fantasia? Na montagem daqui, só perto do final do quarto ato, quando Eugenie faz menção de convocar o povo, de repente, como que chamados, dois ou três pobres coitados, carregando um baú de roupas de estudante e alguns pequenos fardos mimosamente guarnecidos de marcas de comerciantes, passam pelo fundo do palco, que durante o resto do tempo permaneceu vazio de seres vivos. A mim isso parece, ou demais, ou muito pouco. Tenho razão ou não?

3. Ponto, e parágrafo. O texto de Fichte, dado a ler aqui como curiosidade (o filósofo vai ao teatro...), é certamente interessante como documento da concepção estética de uma época. Mais que isso, como um documento de primeira mão: seu autor - embora, ao contrário dos românticos, de Schelling ou de Hegel, jamais tivesse cogitado de elaborar uma filosofia da arte ou sequer de deixar registro de seu gosto artísticoé o criador de uma teoria da imaginaçằo extremamente refinada e, levando até as últimas conseqüências a descoberta kantiana da Reflexão transcendental, operou no plano filosófico uma mutação, que foi decisiva para toda a estética pensada e praticada no período do Romantismo alemão. Compreende-se, nesse contexto, o valor que poderia adquirir, não só pela raridade, um testemunho onde se pode verificar como ele próprio se situa perante uma obra de arte: constatar, por exemplo, o implacável "elitis- 
mo" com que condena toda a concessão ao gosto popular, em favor do espectador ativo, capaz de participar da própria epifania da obra.

Mas, para o leitor de Fichte, o eixo do interesse se desloca para um motivo mais interno. Trata-se, com efeito, de um texto cujo tema é um espetáculo teatral: manifestação cênica da obra, a propósito da qual a palavra Darstellung (Kant traduz: exhibitio), que designa um problema central da especulação fichtiana (e de todo o idealismo alemão), é empregada em seu sentido concreto de mise en scène. e isso num momento em que a questão que ocupa o centro das preocupações de Fichte é justamente a tarefa da Darstellung (da exposição) de seu sistema da doutrina-da-ciência, como o atesta sua correspondência da época: - "Estou, como disse, ainda inteiramente absorvido na doutrina-da-ciência, não para descobri-la ou corrigi-la, mas para elevá-la à clareza pura" (carta a Schiller, 9 de junho de 1803). Um trabalho árduo, que nada tem a ver, é preciso que se note, com a mera redação ou copidescagem de uma obra, entretanto já tida por consumada e sem defeitos, mas requer a reefetuação de suas operações. Reflexão ininterrupta, que consome por si só todas as energias do filósofo, acarretando, até, dificuldades de subsistência: - "Três anos de incessante trabalho na doutrina-da-ciência, quase sem nenhuma ocupação lucrativa, pela absoluta impossibilidade de interromper essa série de meditação, a menos de abandoná-la inteiramente, consumiram o pouco que nos restava" (Ibid.).

Seria um equívoco minimizar, como mera contingência, esse aspecto laborioso associado à tarefa de expor a doutrina-da-ciência: a importância da "exposição" é indissociável da novidade do ponto de vista que ela introduz em filosofia. Sobre esse ponto, a posição de Fichte está definida desde o início. Assentada na exploração, inaugurada por Kant, dos atos transcendentais constitutivos da objetividade, sua teoria da Darstellung do supra-sensivel no sensível - que se configura na distinção entre o espírito (Geist) e a letra (Buchstabe) - não pode ser interpretada metafisicamente, como uma depreciação da Representação em nome da plenitude da Presença. Pelo contrário, "espírito", nesse contexto, é sinônimo de "imaginação criadora", e não significa nenhuma realidade supra-sensivel de que a "letra" fosse uma cópia de segunda mão: é a própria produção do sensível, o qual, como seu produto, a designa legitimamente e lhe assegura a única visibilidade de que ela é capaz. Ê na letra, e não além dela, que o espírito tem corpo e realidade. E admitir que essa realidade é apenas fenomênica não é dotá-la de uma substancialidade metafísica própria nem postular, para além dela, uma outra; é simplesmente reiterar a palavra de Anaxágoras: - Opsis gar ton adelon ta phainomena.

Por isso o discurso especulativo, Darstellung da doutrina-da-ciência. não é um discurso infindável por perseguir em vão a Darstellung de "algo" que estivesse além de toda Darstellung. Retoma-se incessantemente por cumprir à risca sua condição de Darstellung, passagem do supra- 
sensivel ao sensivel que deve ser constantemente reativada para não se fixar nessa dicotomia imaginária, trânsito entre espirito e letra cuja funçâo é impedir que essa dualidade seja reificada em um dualismo estático.

Compreende-se: essa dualidade, como todas as outras que operam nesse discurso (ideal e real, eu e não-eu, consciência e ser...), resolve-se na dialética, especificamente fichtiana, entre termos-limite sempre em suspenso, uma dialética que se põe em movimento no momento em que Fichte situa o foco da reflexão transcendental numa oscilação nuclear da imaginação entre opostos obsolutos - esse intermédio, anterior aos termos da mediação, é propriamente o traçado por onde o pensamento literalmente se esgueira para alcançar a verdade (em si mesma iletrada, afásica) do Transcendental. Criticado dessa maneira, o dualismo reificação dos opostos - revela-se como mero fruto da llusão transcendental, e ter "espírito" (livrar-se da Ilusão) consiste, justamente, em não considerar os dois termos (exterior e interior, exibição e inibição, literalidade e obliteração...) como pares de opostos, mas como fases de pulsação - o que não deixa de afetar todo o panorama da Presença: o visível trabalhado por uma nova rede de visibilidade, onde o discurso filosófico se expõe e se propõe a uma leitura a contracorrente do senso comum e, nesse sentido, como notará Fichte em 1812 (Obras Póstumas, II, 324), a "um ver contra a natureza".

A noção de Darstellung designa, precisamente, essa ruptura interna com a lisura da Representação, e seu órgão próprio é a imaginação, da qual Fichte diz: - "Seja o que for que contenha o fundamento último de uma representação, pelo menos isto é claro, que não é ele mesmo uma representação, e que é preciso que passe por uma transmutação, antes de ser apto a encontrar-se em nossa consciência como matéria de uma representação. A faculdade dessa transmutação é a imaginação. Ela é formadora (Bildnerin). Não falo dela na medida em que chama de volta, liga, ordena representações tidas anteriormente, mas na medida em que, em geral, torna algo representável. Ela é, nessa medida, criadora, criadora da consciência una: dela, nessa função, não se tem consciência, exatamente porque antes dessa função não há consciência nenhuma. $\mathrm{A}$ imaginação criadora. Ela é o espírito." (Geist u. Buchstabe, 19 rascunho de 1794, in: Von den Pflichten des Gelehrten, p. 126.)

Não é o caso de interrogar essa anteriorização da Darstellung à coisa mesma (die Sache selbst), para a qual Fichte já chamara a atenção de Schelling (carta de 31 de maio/7 de agosto de 1801) e que é uma das características que permitem reconhecer nele um dos filósofos-chaves da crise da noção clássica de Representação - ou de mostrar como ela torna possivel abandonar legitimamente a hipótese "evolucionista" que foi, por muitos anos, o único recurso dos comentadores de Fichte para dar conta da multiplicidade das Darstellungen da doutrina-da-ciência. O que sugere o texto sobre a encenação d'A Filha Natural é sobretudo a indagação quanto à continuidade que tem esse sentido "metafórico" da 
Darstellung com seu sentido "próprio", ou: de como a postura fichtiana - de espectador, até - aponta para uma restauração do parentesco original das duas palavras gregas, theoria e theatron, e para sua origem comum no paradigma da visão (theomai).

4. A doutrina-da-ciência, Darstellung de 1604, na qual Fichte trabalhava durante esses "três anos de silêncio e meditação" (como diz Gueroult: Fichte, vol. II, p. 105), é justamente aquela que introduz no vocabulário da filosofia a palavra luz.

A escolha dessa palavra, para designar o princípio único que produz geneticamente, como opostos correlatos, o ser e o conceito, refere-se, primeiro, ao deslocamento do foco da reflexão para a claridade da evidência, mas também ao caráter genético dessa evidência, inobjetivável, que só se mostra, sempre, já cindida em seus resultados: o ser e o ver. Para haver exteriorização ou realização (no sentido de Erscheinung) da luz pura, indica Fichte, "'é preciso que o conceito seja posto, para ser anulado pela luz imediata; pois nisso, justamente, consiste a exteriorizaçào da luz pura; o resultado, porém, e como que o saldo morto dessa exteriorização é o ser em si, o qual, porque a luz pura é ao mesmo tempo anulação do conceito, se torna inconcebível" (Obras Póstumas, II, 118). Resultado dessa ação recíproca da luz consigo mesma, a impenetrabilidade do ser ao conceito nasce, pois, da relação entre ambos e não precisa ser explicada por nenhuma substancialidade ou qualidade oculta. sem que com isso o peso ontológico recaia no pólo "consciência". Conferindo verdadeira autonomia somente à alternância entre os dois pólos ("nós e "o Absoluto), esse "monismo" da Erscheinung da luz é o único que desmonta a alternativa fatal da metafísica e resolve a milenar "dificuldade de toda filosofia que nảo quis ser dualismo e levou a sério a busca da unidade: que, ou nós tínhamos que sucumbir, ou Deus. Nós nâo queríamos, Deus não devia!" (Ibid., 147) Na intelecçào (Einsicht) genética, dissolve-se a autonomia dos dois termos (o "eu" e o "ser") tomados separadamente, e abre-se a única perspectiva capaz de superar a faticidade da disjunção, em que o próprio Kant estacionara, entre sensivel e supra-sensivel. Nessa pura visibilidade, que engendra a visão e o visivel. a doutrina-da-ciência encontra, o que promete, "uma completa soluçào do enigma do mundo, e da consciência" (Ibid. 251).

A doutrina-da-ciência, posta em cena, é justamente a dramatização dessa inteleç̧ão: insustentável como teoria - conceber o inconcebível ela se realiza como teatro - a Erscheinung posta em ação. E Foucault confirma. "Fichte coxo anuncia: eu fissurado/eu dissolvido." (Teatrum Philosophicum)

Desse ponto de vista, não é de estranhar que o primeiro requisito da boa Darstellung. que por sua própria natureza fenomênica tem de desenrolar-se partes extras partes, seja a organicidade do todo, onde, para além da mera acumulação das partes, se mostra sua articulação, 
que faz de cada parte uma pars totalis. Numa totalidade orgânica, como deve ser toda obra viva, os componentes estão interligados por determinação reciproca, e é somente no conjunto que sua apresentação sucessiva recupera todo seu sentido. É o que está dito, desde a exposição de 1794, na advertência ao leitor crítico da doutrina-da-ciência: - "Aos futuros críticos deste escrito solicito atentarem para o todo e considerarem cada pensamento singular do ponto de vista do todo" (Obras, I, 89). E é como contrapartida desse primeiro requisito da Darstellung que a doutrina-da-ciência formula a segunda das duas condições que exige de seu leitor: a capacidade de sustentar duradouramente a atenção, para que "acompanhe os fios do raciocício e não tenha esquecido nada do que precedeu quando estiver no que segue" (Ibid., 88).

Mas a primeira dessas duas condições, pressupostas no leitor, é mais fundamental: "a faculdade de liberdade da intuição interna" (Ibid.), cuja falta pode vedar para sempre o acesso à filosofia transcendental. $\hat{\mathrm{E}}$ ela que permite alcançar a interioridade daquilo que é posto em cena, perceber o jogo de dupla face entre o exterior e o interior e mesmo superar os limites, necessários ou contingentes, da Darstellung, para captar a essência da obra. É a ela que Fichte se refere ao falar em "espirito" e é, enfim, por meio dela que o filósofo liga indissociavelmente, com o rigor que lhe é próprio, a especificidade da doutrina-da-ciência com o paradoxo da Darstellung, no conhecido texto de 1794: - A doutrina-daciência não se comunica pela letra, mas unicamente pelo espirito, porque "suas idéias fundamentais devem ser produzidas em todo aquele que a estuda pela própria imaginação criadora, comọ não poderia deixar de ser em uma ciência que vai até os fundamentos últimos do conhecimento humano, uma vez que toda a operação do espírito humano parte da imaginação, e a imaginação só pode ser apreendida pela imaginação" (Ibid., 285). Não a capacidade de elevar-se, da mera figuração alegórica, a uma comunidade transparente de "espíritos" puros, mas a faculdade de associar-se, pela produtividade da própria imaginação, à operação do "espírito" manifestando-se na "letra" - e, portanto, de tomar parte na produção da Darstellung.

Longe de acarretar, pois, a depreciação da mise em scène - depreciação que só condiria com uma teoria alegórica da Darstellung, viciada pelo dualismo e forçosamente reificante - essa exigência fala, pelo contrário, em nome da associação intrínseca entre "teatro" e "teoria".

Aos espectadores de Goethe - entre os quais se inclui - Fichte faz, em 1803, rigorosamente as mesmas exigências: capacidade de elevar-se acima do limitado da Darstellung, atenção firme e prolongada, sentido para a interioridade daquilo "que se passa nesse palco" - eis as duras qualidades de espírito que a própria obra exige, simplesmente para poder ser vista em sua clareza, pois a cena vive do espectador capaz de captar a "profundeza e simplicidade" ideais da obra. E é à total ausência dessas qualidades, no público de Berlim, que o filósofo se refere, quando se 
queixa de estar vivendo na "capital da barbárie" (Mittelsitz der Barbarei: a Schiller, 20 de julho de 1803). Concluir, entretanto, que diante desse público seria preciso ceder ao estado de coisas e renunciar à apresentação da obra - ou mesmo, numa opção mais conseqüente, à própria produção do "melhor" - seria contraditório com a importância mesma da Darstellung. Somente sua defesa intransigente, sua afirmação sem condescendência a despeito da hostilidade vigente, é compatível com a excelência que deve passar à existência e ocupar o lugar a que faz jus; a cena.

Ê o que confirma a distinção, cuidadosamente marcada por Fichte, entre a encenação e a leitura individual da obra. Apesar dos defeitos da montagem berlinense, a Darstellung ideal do leitor - atualização da obra no elemento da imaginação, obtida no isolamento do gabinete não é melhor por estar mais "próxima" da obra ou por ser sua reprodução mais "fiel". Encontra, por certo, menos entraves em sua liberdade de figuração, mas é inócua, exceto pela insatisfação, que gera, com a Darstellung real. Quaiquer privilégio, entretanto, que pudesse vir a serthe conferido - então, sim, em nome de um elitismo depreciativo - é desmentido pela preocupação de Fichte - ele que não leu a peça e toma contato com ela na sala de espetáculos - com a mise em scène concreta, chegando até aos pormenores do desempenho dos atores, do comportamento da direção e do público, da movimentação de cena e do ritmo do espetáculo. Assim, a apreciação da qualidade dos atores, que vai desde uma piena "presença de espírito", eficiência subjetiva e objetiva do Geist na atuação "inspirada e inspiradora" (begeistert und begeisternd) da primeira atriz, passando pela feliz coincidência entre a característica do ator e um traço da personagem, ou pelo socorro prestado pelo espectador ativo ao suprir um papel dito incorretamente, até o grau mínimo de espírito, seja na opacidade inexpressiva de um ator, que cria um vazio no conjunto ou, efetivamente, no vazio real criado, por obra da direção, com a eliminação de um dos papéis. Assim, a questão final, quanto à presença dos figurantes em cena $\mathrm{e}$ à opção necessária, que não foi feita na montagem, entre uma representação realista e uma representação conven. cional da população: - "Deve ser visível pelo menos um começo da incomensurável vida e faina, que então a fantasia prolonga ao infinito, ou deve o espectador enxergar essa multidão como com o olho da fantasia?"

Nem se pode pensar, por outro lado, que a Darstellung imaginária do leitor se confudisse com a obra mesma, em estado subjetivo, à espera de sua efetuação no real. A obra, em si mesma, é invisível e condição de visibilidade: sua clareza (ou claridade) é a mesma da luz, que torna visível e não se vê, que está em toda parte e em parte nenhuma - e seria contraditório pensar que uma Darstellung, ainda que privilegiada, pudesse esgotá-la, dando-lhe completa objetividade. A relação entre obra e Darstellung, mais uma vez, não é a da reprodução simples, mas a da produção interna. Nesse sentido, a obra dintingue-se tanto da Darste- 
llung real quanto da ideal por funcionar como uma Idéia; é o que o "bom espectador" erblickt: "através do limitado da Darstellung, o ideal dela e, através deste, a obra." E não é por acaso que Fichte, para erradicar todo malentendido que, ainda aqui, poderia reintroduzir o dualismo metafísico, propõe repetidamente a tradução da palavra grega Idea por Gesicht (visão), citando como exemplo a equivalência: "o profeta vê idéias" - "o profeta vê visões".

Com efeito, se Fichte pensa o espetáculo, a cena, a Darstellung, como mero revestimento exterior de uma Idéia, objetivada no mundo dos fenômenos para ser dada a ver, não deixa de ser essa visibilidade a única condição - e indispensável - da própria vida da Idéia, que não tem existência a não ser na exibição.

Assim como não há saber filosófico independente de sua manifestação no discurso, sujeita à variabilidade e à contingência da condição empírica, não há obra teatral sem encenação, e não falta ironia ao comentário do filósofo à opinião do crítico teatral berlinense, que considerava a peça de Goethe uma obra para o gosto da elite, cuja fruição deveria esgotar-se na leitura: - "Ele conclui mais ou menos com o resultado: essas coisas são muito boas para a leitura em gabinete fechado diante de um ou dois amigos, mas o teatro exige coisa diferente. E essa ainda foi a voz mais amistosa, que se fez ouvir publicamente!" (carta de 20 de julho). Ao que, para maior clareza, convém acrescentar: a palavra Theater, na terminologia literária alemã, não se refere nunca à obra escrita (o termo técnico é Drama), mas somente à obra encenada.

Nesse contexto, não deixa de vir a calhar o fato de que a própria peça de Goethe, de que Fichte se faz o ardoroso defensor, tenha como tema a questão da Erscheinung (que se traduz, em vários níveis: "fenômeno", "aparição", "desabrochamento") e traga como mote aqueles dois versos, ditos por Eugenie no segundo ato:

O que é a aparência, se the falta o ser? O ser seria, se não aparecesse?

5. Pondo em ação as vicissitudes de Eugenie, A Filha Natural compõe, em versos decassílabos, um jogo de metáforas ou, como diz Goethe, "um encadeamento de puros motivos" - em torno da passagem do oculto ao aberto, da noite ao dia, do círculo da existência privada ao cenário público, e dos perigos a que esse "expor" é expor-se, por força da rede $(\mathrm{Netz})$ de interesses que estrangula essa passagem à visibilidade.

Eugenie, a de ilustre gênese, é o novo, o puro, o natural que brota (aus hohen Haus entsprossen) ilegitimamente nas falhas de um mundo de aparências fortemente codificadas, onde cada indivíduo só tem o nome de seu papel (o Duque, a Princesa, o Rei, a Preceptora...) e onde a "verdade" de Eugenie, sua alta essência publicamente assumida pecaria por excessiva. Compreende-se: essa rede de aparências, que se esvazia de ser, onde as funções se tornam rótulos sem substância, precisa reificar-se para salvar-se da corrosão que a vai minando. Nela, a manifestação de 
Eugenie, que não pertence a nenhum dos dois partidos, que não tem nenhuma culpa, que ambiciona apenas existir com o brilho (Schein) de sua essência (Wesen), torna-se automaticamente subversiva, provoca o mecanismo da oclusão, do recalque em que todos conspiram, da censura que, da parte do poder politico, não é prova de força, mas sintoma de fraqueza. Ela seria, na linguagem de Fichte, o "espírito" que, para afirmar-se, causa ruptura e deslocamento na superfície da "letra" - e é uma ameaça pela própria excelência de sua natureza, que afinal, simplesmente para existir, tem de aceitar desnaturar-se.

Perigoso, desse modo, para quem se coloca afirmativamente a tarefa e a questão da Darstellung, é o próprio jogo entre a aparência e a essêncią, uma correspondência que não atende espontaneamente à formulação que lhe dá Eugenie no segundo ato.

Seria preciso concluir, também neste caso, que a essência, conforme à solução do quinto ato, só pode salvar-se da destruição renunciando à aparência e recolhendo-se na pura interioridade? $\mathrm{O}$ texto não deixa de indicar que essa interioridade, renúncia à mise en scène no real, é a particularidade da condição burguesa, o círculo da vida privada onde a consciência se esgota na fruição "teórica" de sua própria excelência impedida de atualizar-se. Que essa renúncia possa ser traduzida nos termos de um acatamento da separação - ocidental e moderna - entre "teatro" e "teoria", não seria, em todo caso, uma conclusão tão distante. Afinal, essa interioridade da consciência privada é justamente o lugar, longe do teatro, que a revolução burguesa parece ter reservado para a teoria (cuja Darstellung talvez fosse - como pensou mais tarde, para consolar-se, o século XIX - uma outra revolução).

Insistindo que o lugar da peça de Goethe é o palco, e não a fruição em gabinete fechado, fazendo a crítica da trama de condicionamentos estéticos, culturais - e mesmo metafísicos - em que a crítica, o público e mesmo os responsáveis pelo espetáculo se reconhecem para obstruir a mise en scène d'A Filha Natural, não estaria Fichte, por sua vez, tentando trazer à luz uma estratégia de ocultamento? E não se poderia supor, nesse caso, que o entusiasmo do filósofo pela "obra-mestra do mestre" seria a consequêencia de uma leitura que o faz ver, no palco, uma Darstellung auto-referente? $\mathrm{O}$ que se pode mostrar, pelo menos, é que ele coloca o problema da encenação, em relação a ela, nos mesmos termos em que vive a tarefa da exposição da filosofia. Por isso não poderia concordar com a apreciação retrospectiva de Goethe, em 1825 , a respeito de sua própria obra: - "Minha Eugenie é um encadeamento de puros motivos; e isso não pode fazer fortuna no palco."

6. Uma conjetura dos biógrafos é que Fichte, ao mandar a Schiller uma resenha tão minuciosa da apresentação da peça em Berlim, tinha em mente fazê-la chegar ao conhecimento de Goethe, com quem suas re- 
lações não eram estreitas. Isso realmente aconteceu. No dia 29 de agosto do mesmo ano, em carta enviada a Zeltner, em Berlim, Goethe assinala: - "Fichte escreveu a Schiller uma carta muito bela e amável sobre a Eugenie. Agradeça a ele por mim." 